\title{
GMR
}

\section{Molecular characterization and expression patterns of insulin-like growth factor-binding protein genes in postnatal Nanjiang brown goats}

\author{
S.Y. Zhan, L. Chen, L. Li, L.J. Wang, T. Zhong and H.P. Zhang \\ Farm Animal Genetic Resources Exploration and Innovation Key Laboratory of \\ Sichuan Province, Sichuan Agricultural University, Ya'an, Sichuan, China \\ Corresponding author: H.P. Zhang \\ E-mail: zhp@sicau.edu.cn
}

Genet. Mol. Res. 14 (4): 12547-12560 (2015)

Received May 13, 2015

Accepted August 12, 2015

Published October 16, 2015

DOI http://dx.doi.org/10.4238/2015.October.16.22

\begin{abstract}
Insulin-like growth factor-binding proteins (IGFBPs) play a key role in modulating insulin-like growth factors (IGFs), and are considered candidate genes for growth traits in livestock. In this study, we identified the complete coding sequences of IGFBP-1 to -6 in the Nanjiang brown goat, and assessed gene tissue expression patterns by quantitative polymerase chain reaction. Expression of mRNA for the six gene targets was detectable in liver, heart, and longissimus dorsi (LD) muscle. Expression levels of IGFBP-1, -2 and -5 mRNA were higher in liver than in heart and LD muscle $(P<0.01)$, while IGFBP-6 expression was highest in LD muscle, and IGFBP-3 and -4 were predominantly expressed in LD muscle and liver. Higher IGFBP-2, $-3,-4$, and -6 mRNA levels were observed in LD, compared to triceps brachii muscle $(P<0.01)$. Additionally, the target genes had different temporal expression profiles during postnatal development. Histological assessment of muscle sections revealed a constant increase in muscle fiber diameter with aging. These results suggest that IGFBPs
\end{abstract}


may be important for liver and skeletal muscle development, and may contribute to the biological function of these tissues in goats.

Key words: Insulin-like growth factor-binding protein; Gene expression; Nanjiang brown goat; Cloning

\section{INTRODUCTION}

The insulin-like growth factor (IGF) system, which includes IGF-I and -II; IGF receptors IGF-IR and IGF-IIR; and IGF binding proteins (IGFBP) -1 to -6 , plays a vital role in mammalian growth, development and metabolism. Insulin-like growth factor-l is extremely important in postnatal growth, and mediates most of the anabolic actions of growth hormone $(\mathrm{GH})$ in the peripheral tissues; IGF-II plays a crucial role during embryonic development. Insulin-like growth factors are primarily synthesized in the liver but are expressed in various non-hepatic tissues (Ferry et al., 1999). They exert their biological functions mainly through IGF-IR, a cell surface receptor. During transfer in biological fluids from the area of synthesis to target organs, IGFBPs act as major carrier proteins for IGFs, and the two form a complex structure (Rajaram et al., 1997). This structure prolongs the half-life of circulating IGFs by preventing degradation, and modulates IGF availability and biological activity in local tissues (Hwa et al., 1999). In addition to acting as an intermediary for transporting IGFs, IGFBPs regulate free IGF-I plasma concentrations (Hwa et al., 1999), and prevent hypoglycemia resulting from high IGF circulating concentrations (Duan, 2002).

The IGFBPs are a family of secreted proteins that bind IGFs more strongly than IGF receptors. The IGFBP members have been characterized in mammals (Rajaram et al., 1997; Duan and $\mathrm{Xu}, 2005$ ), and their synthesized levels vary in cells and tissues, suggesting a vital role in regulation of IGF activity (Duan, 2002). In mammals, one or more IGFBP is present in various tissues (Hastie and Haresign, 2006; Baxter and Twigg, 2009; Duan et al., 2010), and each IGFBP displays a unique temporal and spatial expression pattern (Gerrard et al., 1999; Oliver et al., 2005). This suggests that each IGFBP has distinct capabilities and performs different functions, including enhancement or inhibition of IGF biological activity (Siwanowicz et al., 2005), and may be affected by post-transcriptional modifications such as glycosylation, phosphorylation, and proteolysis, and by cell surface associations (Firth and Baxter, 2002). For example, IGFBPs play distinct roles in the regulation of tissue formation and growth, especially in skeletal muscle formation (Oksbjerg et al., 2004; Dayton and White, 2008; Duan et al., 2010).

Currently, information on the IGFBP family, such as IGFBP sequences and their temporal and spatial expression patterns, is limited in goats. To further understand the roles of IGFBPs in goat development, we cloned six IGFBP genes and analyzed their tissue distribution at the mRNA level at five postnatal developmental stages in the Nanjiang brown goat, which is the first artificial breeding new varieties of meat goats in china. These results will provide an insight into understanding the function of IGFBPs in goats.

\section{MATERIAL AND METHODS}

\section{Animals and sample collection}

Female Nanjiang brown goats were raised at the Station of Nanjiang Brown Goat Breeding Center (Nanjiang, Sichuan, China). All experimental procedures were approved by Sichuan 
province, P.R. China Biological Studies Animal Care and Use Committee.

Samples of liver and longissimus dorsi (LD) muscle were collected from goats at five different developmental stages (Three goats for each stages): when animals were 3 (postnatal); 30 and 60 (pre pubertal); 90 (pubertal); or 120 (post pubertal) days of age. For spatial expression analysis, LD (fast-twitch fiber type) and triceps brachii (TB, slow-twitch fiber type) muscle, heart, and liver were collected from three additional post pubertal goats. Tissues were collected within 30 min of euthanasia (intravenous pentobarbital sodium, $100 \mathrm{mg} / \mathrm{kg}$ ) of goats, and were immediately frozen in liquid nitrogen.

\section{RNA extraction and cDNA synthesis}

Total RNA was extracted from the liver of post pubertal age goats using Trizol reagent, according to the manufacturer protocol (Invitrogen, Shanghai, China). Total RNA concentration was measured by Nanodrop (Thermo, Shanghai, China); purity verified from 260/280 nm absorption ratios; and integrity tested by electrophoresis on an $1 \%$ agarose $(\mathrm{w} / \mathrm{v})$ gel. For real-time polymerase chain reactions (PCRs), $2 \mu \mathrm{g}$ total RNA was used for first-strand cDNA synthesis with the following reverse transcription (RT) reaction mixture: $2 \mu \mathrm{L} 5 \mathrm{X}$ Primescript buffer (TaKaRa, Dalian, China); 0.5 $\mu \mathrm{L}$ Primescript RT enzyme mix I; $0.5 \mu \mathrm{L}$ oligo dT primer $(50 \mu \mathrm{M}) ; 0.5 \mu \mathrm{L}$ random 6 mers $(100 \mu \mathrm{M})$; and $4.5 \mu \mathrm{L}$ RNase free $\mathrm{dH} 2 \mathrm{O}$. Reverse transcription was performed at $37^{\circ} \mathrm{C}$ for $15 \mathrm{~min}$ followed by $85^{\circ} \mathrm{C}$ for $5 \mathrm{~s}$, and resulting cDNA was stored at $-20^{\circ} \mathrm{C}$.

\section{Cloning of goat IGFBP family genes}

Primers used for goat IGFBP cDNA cloning (Table 1) were designed against sheep IGFBP sequences (GenBank accession numbers shown in Table 1) and synthesized by the Sangon Biotechnology Company (Shanghai, China). Polymerase chain reactions were performed using $12.5 \mu \mathrm{L} 2 \mathrm{X}$ Taq PCR master mix (TIANGEN, Beijing, China); $1 \mu \mathrm{L}$ each of sense and antisense primers (final $10 \mu \mathrm{M}$ ); $2 \mu \mathrm{L}$ first-strand cDNA as a template; and sterile water to attain a final reaction volume of $25 \mu \mathrm{L}$. Reaction conditions were: 4 min of denaturing at $95^{\circ} \mathrm{C} ; 35$ cycles of amplification at $94^{\circ} \mathrm{C}$ for $30 \mathrm{~s}, \mathrm{Tm}$ (annealing temperature) for $30 \mathrm{~s}$, and $72^{\circ} \mathrm{C}$ for $1 \mathrm{~min}$; and a final extension of $7 \mathrm{~min}$ at $72^{\circ} \mathrm{C}$. Amplified products were separated by electrophoresis on a $1.5 \%$ agarose $(\mathrm{w} / \mathrm{v}) \mathrm{gel}$, and purified using an agarose gel DNA fragment recovery kit (Sangon, Shanghai, China). Products were ligated and inserted into a pMD 19-T vector (Takara, Dalian, China) and transformed into Escherichia coli DH5a cells, and positive clones were selected and sequenced by the Sangon Biotechnology Company (Shanghai, China).

\section{Quantitative real-time PCR and statistical analysis}

Quantitative real-time PCR ( $\mathrm{qPCR}$ ) was performed on six differentially expressed genes - IGFBP-1 to -6 - each normalized to ACTB, GAPDH, and TOP2B levels. Primer sequences are shown in Table 1. Reactions were performed using a Bio-Rad CFX96 real-time PCR system (BioRad, USA) with SYBR Premix Ex Taq II (containing ROX Reference Dye, Takara, Japan). Each reaction $(15 \mu \mathrm{L})$ contained $7.5 \mu \mathrm{L}$ SYBR Premix Ex Taq II; $0.6 \mu \mathrm{L}$ each of $10 \mu \mathrm{M}$ sense and antisense primers; $1.2 \mu \mathrm{L}$ normalized template cDNA; and $5.1 \mu \mathrm{L}$ sterile water. Amplification conditions were $95^{\circ} \mathrm{C}$ for $30 \mathrm{~s}$, and then 40 cycles of $5 \mathrm{~s}$ at $95^{\circ} \mathrm{C}$ and $30 \mathrm{~s}$ at the indicated Tm listed in Table 1. Serial dilutions of sample cDNA were used to generate standard curves for each target, PCR 
efficiency was calculated from the regression slope of the assay, and blank controls were set to monitor contamination. Amplifications were performed in triplicate for each sample. Normalized factors for internal control genes and relative quantities of target genes were analyzed using geNorm software (Vandesompele et al., 2002). Relative gene expression levels were calculated using the $2^{-\Delta \Delta C t}$ method (Livak and Schmittgen, 2001), and data expressed as least square mean \pm standard error of the mean (SEM). Data were analyzed to assess effects of tissue, age, and appropriate interactions. Differences between values were analyzed using the generalized linear model (GLM) and Student's $t$-test analyses in SAS software version 9.0 (SAS, North Carolina, USA). The significance level for statistical analysis was $P<0.05$.

\begin{tabular}{|c|c|c|c|c|c|}
\hline Gene name & & Primer sequence $\left(5^{\prime}-3^{\prime}\right)$ & Size $(b p)$ & annealing temperature $\left({ }^{\circ} \mathrm{C}\right)$ & GenBank accession no. \\
\hline \multirow[t]{4}{*}{ IGFBP-1 } & P1 & F1: TGGCGATGCCCGAAGTCCT & & & \\
\hline & & R1: GCATCTGTTTTCAGTTCTGTAAG & 807 & 62 & 1NM_001145177 \\
\hline & P2 & F2: CACTTGATGACCGAGTCCAC & & & \\
\hline & & R2: TGTAGAGTTCTCGCTGGCAG & 129 & 61.9 & 2HM185495 \\
\hline \multirow[t]{4}{*}{ IGFBP-2 } & P1 & F1: ACCACCATGCAGCCGAGACT & & & \\
\hline & & R1: CATGTCAGAACTCCTGGAAGC & 1077 & 51.3 & 1NM_001009436 \\
\hline & P2 & F2: ATTCCCTACACATCCCCAACT & & & \\
\hline & & R2: GGGTTCACACACCAGCACT & 103 & 59 & 2JQ341160 \\
\hline \multirow[t]{4}{*}{ IGFBP-3 } & P1 & F1: AGCTCGCTGCCGCCCAGT & & & \\
\hline & & R1: GCTGATCATGTCCTTGGCAG & 1019 & 53.4 & 1NM_001159276 \\
\hline & P2 & F2: GGCAGTGAGTCGGAAGAAGA & & & \\
\hline & & R2: GCGAGGTGGGATTTGGAGT & 95 & 59 & 2JQ341161 \\
\hline \multirow[t]{4}{*}{ IGFBP-4 } & P1 & F1: AGCTTGCTAACTTCCTCGGC & & & \\
\hline & & R1: AAGCCAGGACTCAGACCTAG & 1017 & 55.7 & 1NM 001134302 \\
\hline & P2 & F2: TCTGACAAGGATGAGGGTGAC & & & \\
\hline & & R2: GTGCTCCGGTCTCGAATTT & 107 & 59 & 2JQ341162 \\
\hline \multirow[t]{4}{*}{ IGFBP-5 } & P1 & F1: AGACTCGGAGAAGATGGTGCTC & & & \\
\hline & & R1: TGGGATGGGGTGAGGGAAAGA & 861 & 58 & 1NM_001129733 \\
\hline & P2 & F2: AGAGAGACTCCCGTGAGCAT & & & \\
\hline & & R2: ACGAACTTGGACTGGGTCAG & 159 & 61.4 & 2KC485342 \\
\hline \multirow[t]{4}{*}{ IGFBP-6 } & P1 & F1: AGCTTTGCTGCGACTGCTCT & & & \\
\hline & & R1: ATGCTCCTGCCAGTGGCCTT & 801 & 59 & 1NM_001134308 \\
\hline & P2 & F2: TAAGGAGAGTAAGCCCCAAGC & & & \\
\hline & & R2: AGGGACCCATCTCAGTGTCTT & 137 & 59 & 2JQ341163 \\
\hline \multirow{2}{*}{ ACTB } & & F: CCTGCGGCATTCACGAAACTAC & & & \\
\hline & & R: ACAGCACCGTGTTGGCGTAGAG & 87 & 59.7 & 1NM_001009784 \\
\hline \multirow[t]{2}{*}{ GAPDH } & & F: GCAAGTTCCACGGCACAG & & & \\
\hline & & R: GGTTCACGCCCATCACAA & 249 & 59.2 & 1XM_005680968 \\
\hline \multirow[t]{2}{*}{ TOP2B } & & F: GTGTGGAGCCTGAGTGGTATA & & & \\
\hline & & R: AAGCATTCGCCTGACATTGTT & 137 & 59.0 & 1XM_005698949 \\
\hline
\end{tabular}

"P1" primers were used for PCR of IGFBPs, "P2" primers were used for real-time quantitative PCR. 1 Sequences used were from GenBank, 2 Sequences were generated from cloning and sequencing.

\section{Morphologic and morphometric analysis}

Skeletal muscle fragments were collected from eight sections of LD and TB muscle samples from three ewes at each of the developmental stages assessed. Samples were immersed in n-hexane, cooled in liquid nitrogen, and then stored at $-80^{\circ} \mathrm{C}$ in a freezer until sectioning. Transverse sections $\left(10 \mu \mathrm{m}\right.$ thick) were obtained using a $-20^{\circ} \mathrm{C}$ cryostat and stained with hematoxylin and eosin (HE) (Fischer et al., 2008). 


\section{RESULTS}

\section{Goat IGFBP bioinformatics analysis}

Sequences of IGFBP-1 to -6 cDNA were cloned from goat liver and submitted to GenBank with the following accession numbers: IGFBP-1 (HM185495); IGFBP-2 (JQ341160); IGFBP-3 (JQ341161); IGFBP-4 (JQ341162); IGFBP-5 (KC485342); and IGFBP-6 (JQ341163). The open reading frames of $I G F B P-1,-2,-3,-4,-5$, and -6 were $792,954,1019,777,819$, and $711 \mathrm{bp}$, respectively; these encoded 263, 317, 293, 258, 272, and 236 amino acids, respectively. The ArgGly-Asp (RGD) sequence was detected at the C-terminal domain of IGFBP-1 and -2 (Figure 1). Heparin-binding motifs (YKKKQCRP, YKRKQCKP and YRKRQCRS) were found in the C-terminal domains of IGFBP-3, -5 and -6 , and putative nuclear localization signals (RPSKGRK and PSRGRK) were detected in the C-terminal domains of IGFBP-3 and -5 (Figure 1). Phylogenetic (Figure 2) and homology (Table 2) analyses indicated that goat IGFBP sequences were similar to orthologs in other mammals.

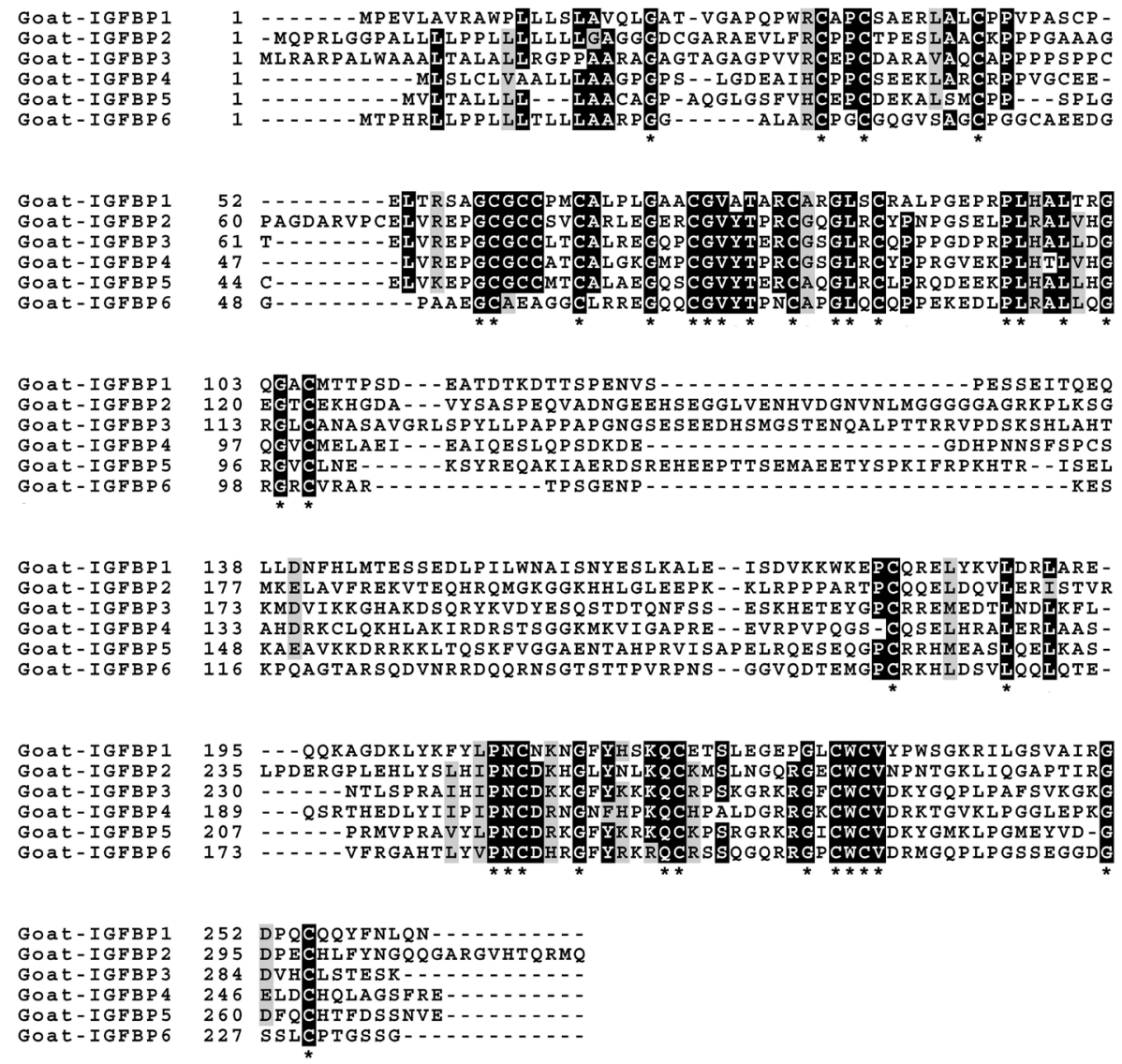

Figure 1. Alignment of goat IGFBP-1, - $2,-3,-4,-5$, and -6 amino acid sequences Conserved cysteine residues are indicated by an asterisk $\left({ }^{*}\right)$. Black blocks represent residues conserved in all goat IGFBPs; gray blocks indicate residues conserved in approximately $80 \%$ of goat IGFBPs. 


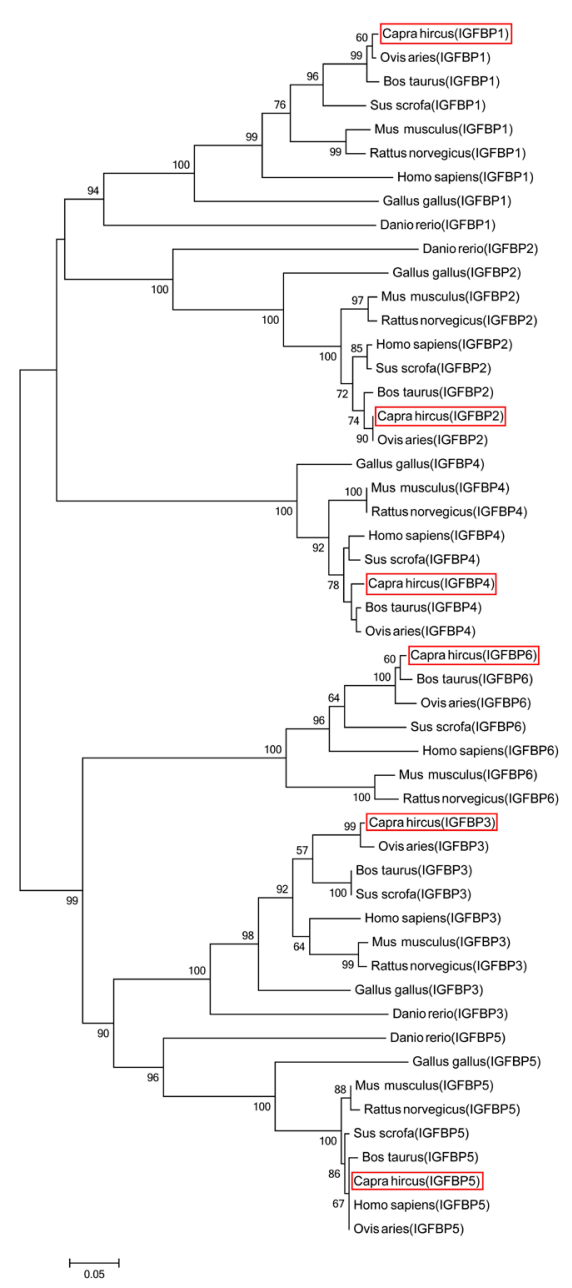

Figure 2. Phylogenetic tree of goat IGFBP-1 to -6 genes Constructed by the Neighbour-Joining method (1000 bootstraps) using MEGA 4.0. Bootstrap values are shown at branch points. Scale bar indicates the number of changes inferred as having occurred along each branch. Accession numbers for IGFBP-1: Capra hircus (HM185495), Ovis aries (NP_001138649), Bos taurus (NP_776979), Sus scrofa (NP_001182034), Homo sapiens (NP_000587), Mus musculus (NP_032367), Rattus norvegicus (NP_037276), Gallus gallus (NP_001001294), and Danio rerio (NP_775390). Accession numbers for IGFBP-2: Capra hircus (JQ341160), Ovis aries (NP_001009436), Bos taurus (NP_776980), Sus scrofa (NP_999168), Homo sapiens (NP_000588), Mus musculus (NP_032368), Rattus norvegicus (NP_037254), Gallus gallus (NP_990690), and Danio rerio (NP_571533). Accession numbers for IGFBP-3: Capra hircus (JQ341161), Ovis aries (NP_001152748), Bos taurus (NP_776981), Sus scrofa (NP_001005156), Homo sapiens (NP_000589), Mus musculus (NP__032369), Rattus norvegicus (NP_036720), Gallus gallus (NP_001094504), and Danio rerio (NP_991314). Accession numbers for IGFBP-4: Capra hircus (JQ341162), Ovis aries (NP_001127774), Bos taurus (NP_776982), Sus scrofa (NP_001116601), Homo sapiens (NP_001543), Mus musculus (NP_034647), Rattus norvegicus (NP_001004274), and Gallus gallus (NP_989684). Accession numbers for IGFBP-5: Capra hircus (KC485342), Ovis aries (NP_001123205), Bos taurus (NP_001098797), Sus scrofa (NP_999264), Homo sapiens (NP_000590), Mus musculus (NP_034648), Rattus norvegicus (NP_036949), Gallus gallus (XP_422069), and Danio rerio (NP_001119935). Accession numbers for IGFBP-6: Capra hircus (JQ341163), Ovis aries (NP_001127780), Bos taurus (NP_001035585), Sus scrofa (NP_001093660), Homo sapiens (NP_002169), Mus musculus (NP_032370), and Rattus norvegicus (NP_037236). 


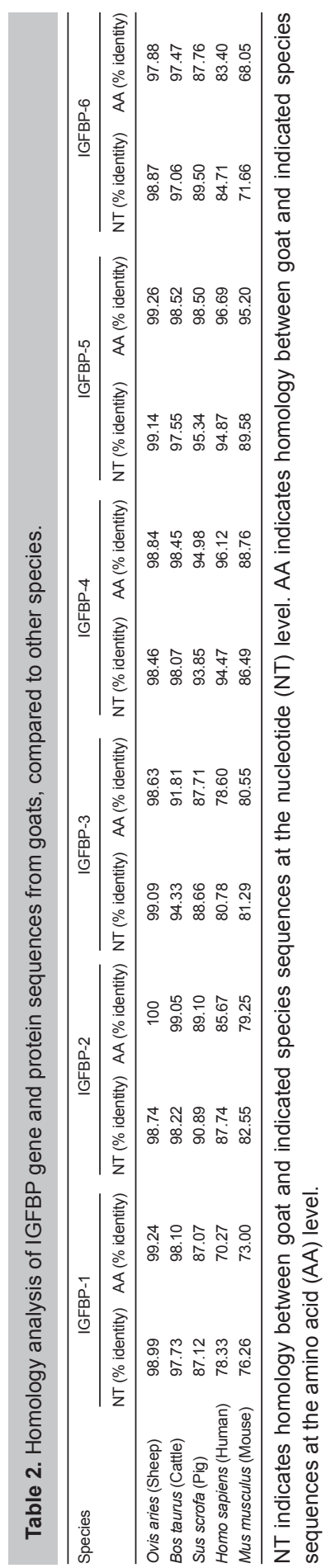




\section{Expression patterns of goat IGFBP}

Tissue expression patterns of goat /GFBP-1 to -6 were assessed in liver, heart, and LD and TB muscle. IGFBP-1 (Figure $3 \mathrm{~A}$ ), -2 (Figure $3 \mathrm{~B}$ ) and -5 (Figure $3 \mathrm{E}$ ) were predominantly expressed in liver $(P<0.05)$, with very low levels in heart and LD muscle. Levels of IGFBP-3 and -4 mRNA were high in liver and LD muscle $(P<0.05)$, and lowest in heart (Figure $3 C$ and $D)$. Expression of IGFBP-6 was detected mainly in LD muscle $(P<0.05)$, followed by heart and liver (Figure $3 F$ ).

Given muscle types, we further performed qPCR to analyze the expression pattern of IGFBPs in TB (composed mostly of type I, slow-twitch oxidative fibers) and LD (predominantly type Illb, fast twitch glycolytic fibers) muscle samples (Peinado et al., 2004; Choi and Kim, 2009). A higher abundance of IGFBP-2, $-3,-4$, and -6 mRNA was found in LD, compared to TB muscle (Figure $3 \mathrm{~B}$ to $\mathrm{D}$, and $\mathrm{F})(\mathrm{P}<0.05)$, while there was no significant difference in IGFBP-1 and -5 expression between muscle types (Figure $3 \mathrm{~A}$ and $\mathrm{E}$ ).
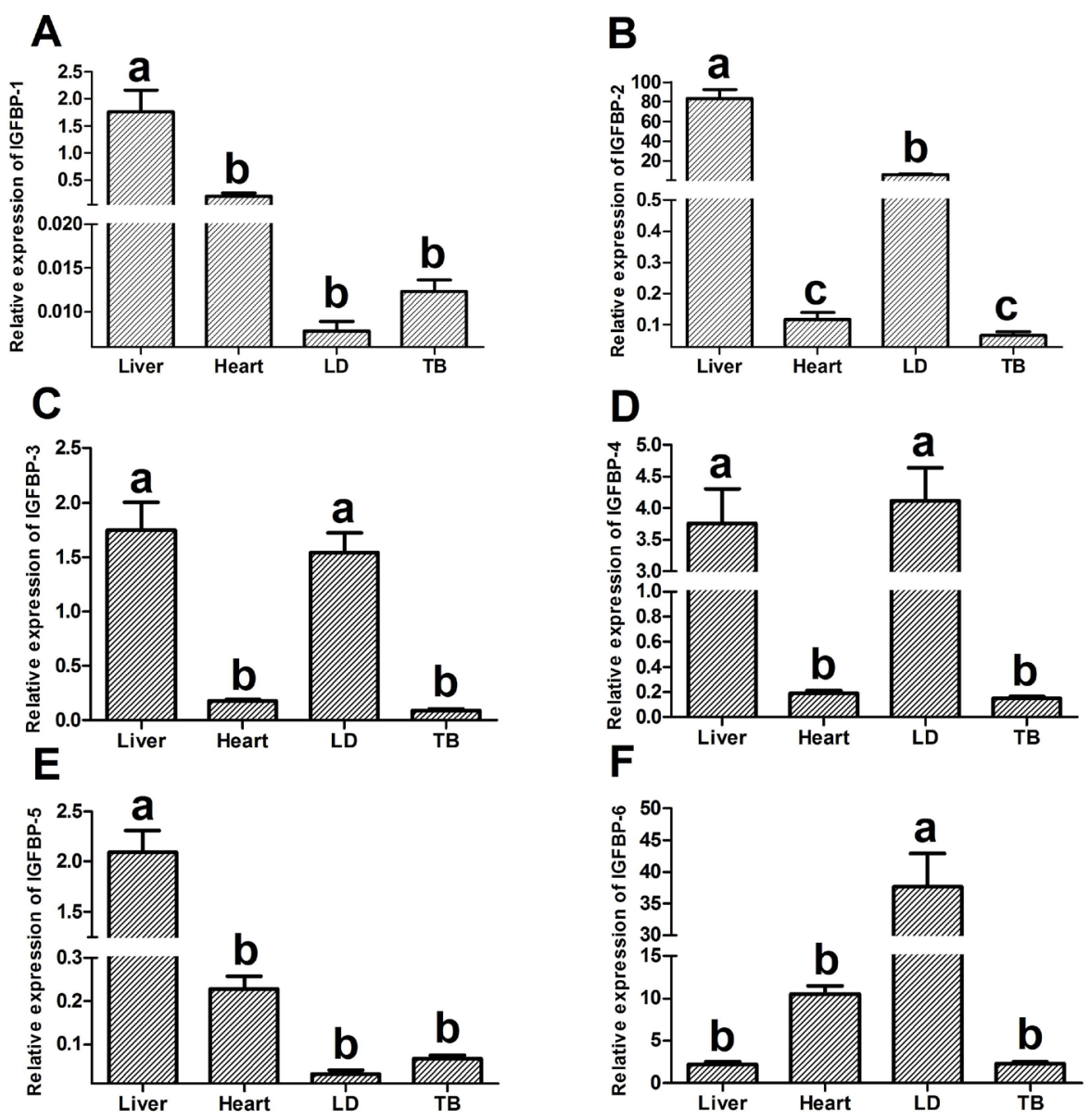

$\mathbf{F}$

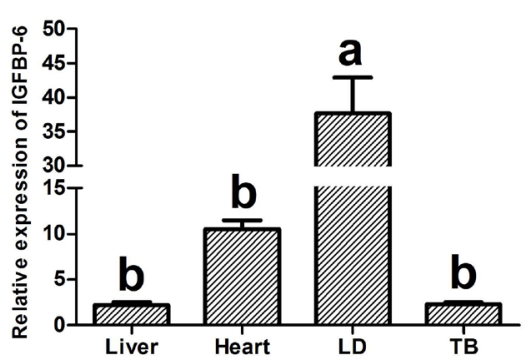

Figure 3. Spatial expression profile of IGFBPs in liver, heart, and LD and TB muscle of 120-day-old goats IGFBP-1 $(A),-2(B),-3(C),-4(D),-5(E)$, and $-6(F)$. Values are presented as mean \pm SEM; those with different letters are significantly different $(P<0.05)$; LD: longissimus dorsi muscle, TB: triceps brachii muscle. 


\section{Temporal expression profiles of IGFBP during liver and LD muscle development in goats}

In the liver, expression of IGFBP-1 mRNA was down-regulated from 0 to 30 days, increased and reached its highest level at 60 days, then decreased to 120 days (Figure $4 \mathrm{~A}$ ). Expression of IGFBP-2 and -5 mRNA was up regulated from 0 to 90 days then decreased to 120 days (Figure $4 \mathrm{~B}$ and $\mathrm{E}$ ). Expression of IGFBP-3 and -4 mRNA decreased from 3 to 30 days, then up-regulated strongly, attaining peaks at 120 days (Figure $4 \mathrm{C}$ and D). Expression of IGFBP-6 showed no significant difference during postnatal liver development (Figure $4 \mathrm{~F}$ ).

In LD muscle, IGFBP-1 and -5 mRNA levels did not change during postnatal development (Figure $4 \mathrm{~A}$ and $\mathrm{E}$ ); IGFBP-2, -3 and -4 exhibited similar expression trends with an "up-down-up" expression pattern (Figure 4 B to D); and IGFBP-6 was down-regulated from days 3 to 90 , then up-regulated slightly (Figure $4 \mathrm{~F}$ ).
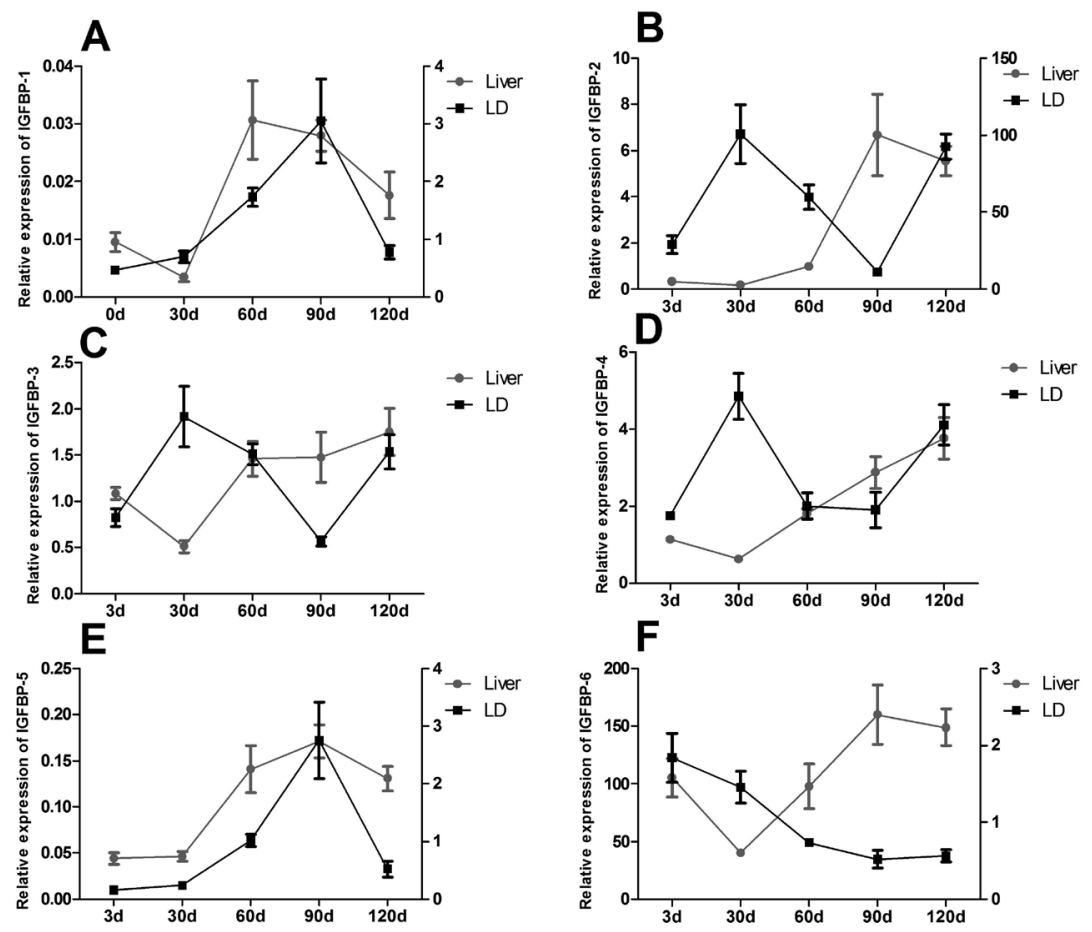

Figure 4. mRNA levels of IGFBP in different liver and LD muscle developmental stages in the Nanjiang brown goat IGFBP-1 (A), $-2(B),-3(C),-4(D),-5(E)$, and $-6(F)$. Vertical lines represent the SEM. Right $Y$ axis is expression levels in liver; left $Y$ axis is expression in LD muscle; LD: longissimus dorsi muscle, d: days.

\section{Muscle fiber diameter and association with IGFBP expression in muscles}

Following an increase in body weight, overall muscle fiber diameter increased across the growth time points assessed (Figure 5). There were no significant relative differences in IGFBP expression over this time (data not shown). 


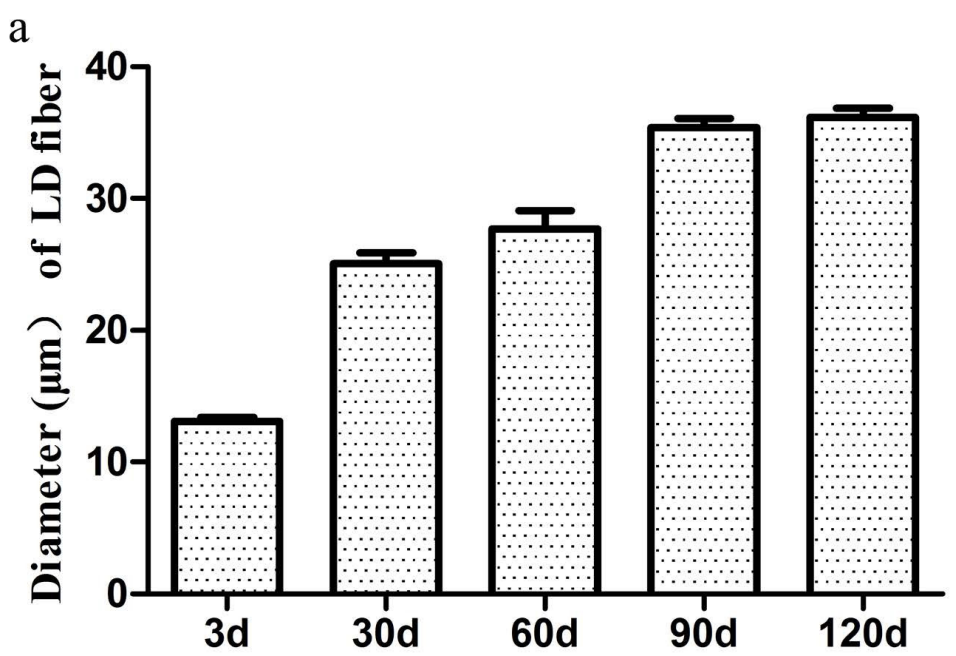

$\mathrm{b}$

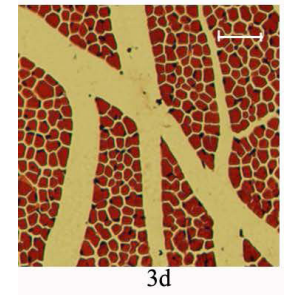

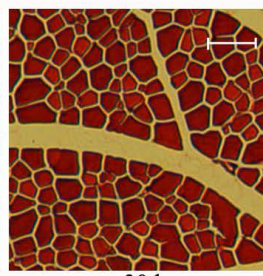

$30 \mathrm{~d}$

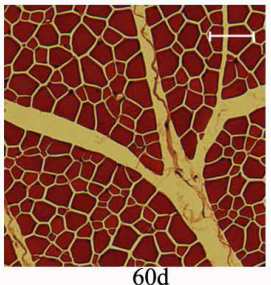

$60 \mathrm{~d}$

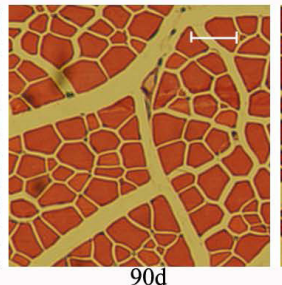

$90 \mathrm{~d}$

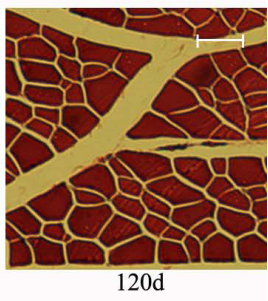

$120 d$

Figure 5. Longissimus dorsi (LD) muscle fiber diameter (a) and transverse sections at five postnatal developmental time points. Bars $=50 \mu \mathrm{m}$.

\section{DISCUSSION}

\section{Characterization of IGFBP-1 to -6 in goats}

Complete coding sequences were identified for goat IGFBP-1 to -6 . Based on these primary sequences, phylogenetic analysis segregated each goat IGFBP into its corresponding clade with very high bootstrap support values. Similar to other mammalian IGFBPs, sequence alignment of the six goat IGFBPs revealed common domains, conserved $\mathrm{N}$ - and $\mathrm{C}$-terminal domains, and a variable central L-domain.

A total of 18 or 16 cysteine residues were located in the conserved $\mathrm{N}$-terminal domain (12 cysteines in IGFBP-1 to -5 ; 10 in IGFBP-6) and conserved C-terminal domain ( 6 cysteines) of the proteins. These cysteine residues have been previously demonstrated to be involved in intradomain disulphide bond formation (Hwa et al., 1999). Within the $\mathrm{N}$-terminal domain, a local motif (GCGCCxxC) was also well conserved among goat IGFBPs, with the exception of IGFBP-6, which substituted a GCAEAGGC sequence, thereby accounting for the two absent cysteine residues in this gene. It is hypothesized that this motif has an important role in interactions with IGFs (Hwa et al., 1999; Duan and Xu, 2005).

The L-domain of IGFBPs is considered to be a structural hinge between the $\mathrm{N}$ - and 
C-terminal domains (Hwa et al., 1999). We observed that goat IGFBPs had highly variable L-domains without cysteine residues, with the exception of IGFBP-4, which harbored two cysteine residues. Since these two cysteine residues are independently presented in this region, they are unlikely to be involved in disulphide bond formation. In addition, the L-domain of each IGFBP may maximize specific, high-affinity IGF binding (Hwa et al., 1999).

Similarly to the $\mathrm{N}$-terminal, the $\mathrm{C}$-terminal domain was highly conserved among goat IGFBPs. The C-terminal has been found to be essential in high-affinity and stable IGF-binding (Hwa et al., 1999; Baxter, 2000). In addition, sequences of the C-terminal domain of goat IGFBPs showed close similarity to the thyroglobin-type-1 domain, characterized by the presence of six cysteine residues and the conserved CWCV motif. It has been hypothesized that the thyroglobin sequence motif might have an important role in binding between IGFBPs and IGFs and the extracellular matrix (Pedroso et al., 2009). In addition, mammalian IGFBP-1 and -2 have an arginine-glycine-glutamate (RGD) sequence in their C-terminal, and this motif has been shown to mediate binding to integrins (Hwa et al., 1999). Another prominent motif found in the C-terminal domain of goat IGFBP-3, -5 and -6 was the heparin-binding motif. Studies have shown that the heparin-binding sequences can associate with glycosaminoglycans, resulting in reduced affinity of IGFBPs to IGFs (Arai et al., 1994).

\section{Tissue distribution of IGFBP in goats}

Previous investigations have reported that IGFBPs were expressed in a wide range of tissues, including liver, kidney, heart, stomach, lung, and muscle (Peng et al., 1996; Saito et al., 2003; Pedroso et al., 2009). Our study indicated that all IGFBPs were expressed in the tissues tested. In the liver, IGFBP-1, $-2,-3,-4$, and -5 had relatively high levels compared to other tissues, indicating liver is the major source of IGFBPs in postnatal life, when these proteins function as endocrine factors. This is consistent with observations in other species in which the liver is the main source of circulating IGFBPs (Green et al., 1994; Zhou et al., 2003). In addition to the liver, myoblast and skeletal muscle have been showed to synthesize IGFBPs (Oliver et al., 2005; Duan et al., 2010). Similarly, in our study, we found that IGFBPs were expressed in skeletal muscle, with the highest levels of IGFBP-6 mRNA detected in LD muscle. Previous studies have shown that IGFs play critical roles in skeletal muscle growth and hypertrophy (Duan et al., 2010). During postnatal growth in vivo or in fully differentiated muscle cells in culture, IGF-I stimulates the rate of protein synthesis and inhibits its degradation rate, thereby enhancing myofiber hypertrophy (Oksbjerg et al., 2004). Our results indicate that as the major carrier proteins for IGFs, IGFBPs also play specialized roles during muscle growth.

\section{Differential expression of IGFBP genes in two different muscle types}

In LD muscle, which contains mostly fast twitch glycolytic fibers, IGFBP-2, -3, -4 and -6 were expressed at higher levels than in TB muscle, which contains predominantly slow-twitch oxidative fibers. Meanwhile, no significant difference in expression levels of IGFBP-1 and -5 was observed between LD and TB muscles. Fiber type composition can vary markedly in different species and in different muscle types, depending on their function (Klont et al., 1998). Previous observations that the amount of IGFBP was associated with specific muscle fiber populations, suggest a role for IGFBPs in the development of specific muscle fiber types during prenatal muscle formation (Gerrard et al., 1999). The production and secretion pattern of IGFs from muscle cells to the tissue culture medium may also depend on the type of muscle within a species (Oksbjerg et al., 
2004). Passive stretch induced increases in IGF-I mRNA expression within individual muscle fibers and in the percentage of slow-twitch oxidative fibers (Kocamis et al., 2001). Our data indicate that IGFBPs might be related to meat quality parameters that are affected by muscle fiber type.

In mammals, the number of muscle fibers is determined at birth, and muscle fibers only increase in diameter after birth (Parker et al., 2003). The postnatal growth of animals is mainly reflected in body weight, fatness and body composition, which also results in an increase of muscle fiber diameter, as previously reported (White et al., 2010). This is consistent with our results from morphologic and morphometric analysis.

\section{Developmental expression of IGFBPs}

Studies on IGFBPs roles in tissue development have shown that IGFBPs play critical roles in mammalian growth and development (Peng et al., 1996; Gerrard et al., 1999; Pell et al., 2005; Farin et al., 2010). In our study, three IGFBP mRNA expression patterns were observed across time during postnatal liver development: "up-down" (IGFBP-1, -2 and -5), "down-up" (IGFBP-3 and -4), and fluctuating "up-down" (IGFBP-6) expression. In muscle, we observed that IGFBP-1 and -5 showed an "up-down" expression pattern, but there was no significant difference between each stages of age. Two other expression patterns were observed: "up-down-up" (IGFBP-2, -3 and -4), and a consistently low expression (IGFBP-6). Our observations of IGFBP-1 and -3 expression patterns are consistent with those in pigs (Peng et al., 1996), while IGFBP-2 expression is in accordance with studies in sheep (Delhanty and Han, 1993). Studies in pigs have shown that in fetal liver and muscle tissue, IGFBP-2, -4 , and -5 expression is time and tissue dependent, while IGFBP-4 and -5 are modulators of myogenesis (Gerrard et al., 1999).

Insulin-like growth factors play critical roles in liver and muscle development. In IGFBP-1 knockout mice, liver tissue was found to have increased sensitivity to apoptotic stimuli (Leu et al., 2003), and IGFBP-2 knockout mice exhibited enlarged livers (Wood et al., 2000). Mice null for IGFBP-3, -4 , and -5 showed significantly diminished postnatal growth and enhanced glucose metabolism, and demonstrated significantly reduced quadriceps muscle size (Ning et al., 2006). In addition, IGFBP-4 knockout mice show reduced prenatal growth (Ning et al., 2008). More recent studies have shown that IGFBP-5 plays a key role in muscle growth and differentiation (Mukherjee et al., 2008; Duan et al., 2010; Safian et al., 2012). However, IGFBP-5 knockout mice had no obvious abnormalities in muscle development, probably due to the compensatory effects of other IGFBPs (Ning et al., 2007). Furthermore, in vascular smooth muscle cell, IGFBP-2 or IGFBP-4 exert inhibitory effects on IGF-I-induced DNA synthesis, while IGFBP-5 potentiates the mitogenic effect of IGF-I (Hsieh et al., 2003). The genes IGFBP-3 and -5 have been shown to have intrinsic biological activities that are IGF-independent (Firth and Baxter, 2002; Duan and Xu, 2005; Duan et al., 2010). Taken together, these studies demonstrate that IGFBPs are expressed in spatially and temporally restricted fashions, and each play distinct roles in regulating tissue development. But the exact mechanism for this result remains unknown and awaits thorough investigation.

\section{Conflicts of interest}

The authors declare no conflicts of interest.

\section{ACKNOWLEDGMENTS}

Research financially supported by the National Spark Key Program (grant \# 
2012GA810001), and the Sichuan Province Science and Technology Support Program (grant \# 2011NZ0003 and \#2011NZ0099-36).

\section{REFERENCES}

Arai T, Parker A, Busby W Jr. and Clemmons DR (1994). Heparin, heparan sulfate, and dermatan sulfate regulate formation of the insulin-like growth factor-I and insulin-like growth factor-binding protein complexes. J. Biol. Chem. 269: 20388-93.

Baxter RC (2000). Insulin-like growth factor (IGF)-binding proteins: interactions with IGFs and intrinsic bioactivities. Am. J. Physiol. Endocrinol. Metab. 278: E967-976.

Baxter RC and Twigg SM (2009). Actions of IGF binding proteins and related proteins in adipose tissue. Trends Endocrinol. Metab. 20: 499-505.

Brameld JM, Mostyn A, Dandrea J, Stephenson TJ, et al. (2000). Maternal nutrition alters the expression of insulin-like growth factors in fetal sheep liver and skeletal muscle. J. Endocrinol. 167: 429-437.

Choi YM and Kim BC (2009). Muscle fiber characteristics, myofibrillar protein isoforms, and meat quality. Livest. Sci. 122: 105-118.

Dayton WR and White ME (2008). Cellular and molecular regulation of muscle growth and development in meat animals. J. Anim. Sci. 86: E217-225.

Delhanty PJ and Han VK (1993). The expression of insulin-like growth factor (IGF)-binding protein-2 and IGF-II genes in the tissues of the developing ovine fetus. Endocrinology 132: 41-52.

Duan C (2002). Specifying the cellular responses to IGF signals: roles of IGF-binding proteins. J. Endocrinol. 175: 41-54.

Duan C, Ren H and Gao S (2010). Insulin-like growth factors (IGFs), IGF receptors, and IGF-binding proteins: roles in skeletal muscle growth and differentiation. Gen. Comp. Endocrinol. 167: 344-351.

Duan C and Xu Q (2005). Roles of insulin-like growth factor (IGF) binding proteins in regulating IGF actions. Gen. Comp. Endocrinol. 142: 44-52.

Farin CE, Alexander JE and Farin PW (2010). Expression of messenger RNAs for insulin-like growth factors and their receptors in bovine fetuses at early gestation from embryos produced in vivo or in vitro. Theriogenology. 74: 1288-1295.

Ferry RJ Jr, Cerri RW and Cohen P (1999). Insulin-like growth factor binding proteins: new proteins, new functions. Horm. Res. 51: 53-67.

Firth SM and Baxter RC (2002). Cellular actions of the insulin-like growth factor binding proteins. Endocr. Rev. 23: 824-854.

Fischer AH, Jacobson KA, Rose J and Zeller R (2008). Hematoxylin and eosin staining of tissue and cell sections. CSH Protoc. 3: $1-2$.

Gerrard DE, Okamura CS and Grant AL (1999). Expression and location of IGF binding protein-2,-4 and -5 in developing fetal tissues. J. Anim. Sci. 77: 1431-1441.

Green BN, Jones SB, Streck RD, Wood TL, et al. (1994). Distinct expression patterns of insulin-like growth-factor bindingproteins 2 and 5 during petal and postnatal-development. Endocrinology 134: 954-962.

Hastie PM and Haresign W (2006). Expression of mRNAs encoding insulin-like growth factor (IGF) ligands, IGF receptors and IGF binding proteins during follicular growth and atresia in the ovine ovary throughout the oestrous cycle. Anim. Reprod. Sci. 92: 284-299.

Hsieh T, Gordon RE, Clemmons DR, Busby WH Jr, et al. (2003). Regulation of vascular smooth muscle cell responses to insulin-like growth factor (IGF)-I by local IGF-binding proteins. J. Biol. Chem. 278: 42886-42892.

Hwa V, Oh Y and Rosenfeld RG (1999). The insulin-like growth factor-binding protein (IGFBP) superfamily. Endocr. Rev. 20: 761-787.

Klont RE, Brocks L and Eikelenboom G (1998). Muscle fibre type and meat quality. Meat Sci. 49S1: S219-229.

Kocamis H, McFarland DC and Killefer J (2001). Temporal expression of growth factor genes during myogenesis of satellite cells derived from the biceps femoris and pectoralis major muscles of the chicken. J. Cell. Physiol. 186: $146-152$.

Leu JI, Crissey MA, Craig LE and Taub R (2003). Impaired hepatocyte DNA synthetic response posthepatectomy in insulinlike growth factor binding protein 1-deficient mice with defects in C/EBP beta and mitogen-activated protein kinase/ extracellular signal-regulated kinase regulation. Mol. Cell. Biol. 23: 1251-1259.

Livak KJ and Schmittgen TD (2001). Analysis of relative gene expression data using real-time quantitative PCR and the 2(-Delta Delta C(T)) Method. Methods 25: 402-408.

Mukherjee A, Wilson EM and Rotwein P (2008). Insulin-like growth factor (IGF) binding protein-5 blocks skeletal muscle differentiation by inhibiting IGF actions. Mol. Endocrinol. 22, 206-215.

Ning Y, Hoang B, Schuller AG, Cominski TP, et al. (2007). Delayed mammary gland involution in mice with mutation of the insulin-like growth factor binding protein 5 gene. Endocrinology 148: 2138-2147. 
Ning Y, Schuller AG, Bradshaw S, Rotwein P, et al. (2006). Diminished growth and enhanced glucose metabolism in triple knockout mice containing mutations of insulin-like growth factor binding protein-3, -4, and -5. Mol. Endocrinol. 20: 21732186.

Ning Y, Schuller AG, Conover CA and Pintar JE (2008). Insulin-like growth factor (IGF) binding protein-4 is both a positive and negative regulator of IGF activity in vivo. Mol. Endocrinol. 22: 1213-1225.

Oksbjerg N, Gondret F and Vestergaard M (2004). Basic principles of muscle development and growth in meat-producing mammals as affected by the insulin-like growth factor (IGF) system. Domest. Anim. Endocrinol. 27: 219-240.

Oliver WT, Rosenberger J, Lopez R, Gomez A, et al. (2005). The local expression and abundance of insulin-like growth factor (IGF) binding proteins in skeletal muscle are regulated by age and gender but not local IGF-I in vivo. Endocrinology 146: 5455-5462.

Parker MH, Seale P and Rudnicki MA (2003). Looking back to the embryo: defining transcriptional networks in adult myogenesis. Nat. Rev. Genet. 4: 497-507.

Pedroso FL, Fukada $\mathrm{H}$ and Masumoto T (2009). Molecular characterization, tissue distribution patterns and nutritional regulation of IGFBP-1, -2, -3 and -5 in yellowtail, Seriola quinqueradiata. Gen. Comp. Endocrinol. 161: 344-353.

Peinado B, Latorre R, Vaquez-Auton JM, Poto A, et al. (2004). Histochemical skeletal muscle fibre types in the sheep. Anat. Histol. Embryol. 33: 236-243.

Pell JM, Salih DA, Cobb LJ, Tripathi G, et al. (2005). The role of insulin-like growth factor binding proteins in development. Rev. Endocr. Metab. Disord. 6: 189-198.

Peng M, Pelletier G, Palin MF, Veronneau S, et al. (1996). Ontogeny of IGFs and IGFBPs mRNA levels and tissue concentrations in liver, kidney and skeletal muscle of pig. Growth Dev. Aging 60: 171-187.

Rajaram S, Baylink DJ and Mohan S (1997). Insulin-like growth factor-binding proteins in serum and other biological fluids: regulation and functions. Endocr. Rev. 18: 801-831.

Safian D, Fuentes EN, Valdes JA and Molina A (2012). Dynamic transcriptional regulation of autocrine/paracrine igfbp1, 2, $3,4,5$, and 6 in the skeletal muscle of the fine flounder during different nutritional statuses. J. Endocrinol. 214: 95-108.

Saito T, Akutsu S, Urushiyama T, Ishibashi K, et al. (2003). Changes in the mRNA expressions of insulin-like growth factors, their receptors, and binding proteins during the postnatal development of rat masseter muscle. Zoolog. Sci. 20: 441-447.

Siwanowicz I, Popowicz GM, Wisniewska M, Huber R, et al. (2005). Structural basis for the regulation of insulin-like growth factors by IGF binding proteins. Structure 13: 155-167.

Vandesompele J, De Preter K, Pattyn F, Poppe B, et al. (2002). Accurate normalization of real-time quantitative RT-PCR data by geometric averaging of multiple internal control genes. Genome Biol. 3: RESEARCH0034.

White RB, Bierinx AS, Gnocchi VF and Zammit PS (2010). Dynamics of muscle fibre growth during postnatal mouse development. BMC Dev. Biol. 10: 21.

Wood TL, Rogler LE, Czick ME, Schuller AG, et al. (2000). Selective alterations in organ sizes in mice with a targeted disruption of the insulin-like growth factor binding protein-2 gene. Mol. Endocrinol. 14: 1472-1482.

Zhou R, Diehl D, Hoeflich A, Lahm H, et al. (2003). IGF-binding protein-4: biochemical characteristics and functional consequences. J. Endocrinol. 178: 177-193. 